\title{
Projecting Groundwater Variability in Data-scarce Tropical Savanna Region of India
}

\author{
SURAJ JENA ${ }^{1}$, Rabindra Panda ${ }^{1}$, Meenu Ramadas ${ }^{1}$, Binayak Mohanty ${ }^{2}$, Alok \\ Samantaray $^{1}$, and Susanta Pattanaik ${ }^{3}$ \\ ${ }^{1}$ Indian Institute of Technology Bhubaneswar \\ ${ }^{2}$ Texas A\&M University System \\ ${ }^{3}$ Directorate of Groundwater Development
}

September 21, 2020

\begin{abstract}
For regional sustainability, spatio-temporal variability of groundwater level (GWL) in tropical savanna climatic region with heavily stressed aquifers needs future projection skills by taking hydrological, geological, and climatic (HGC) controls into consideration. This study analyzed the spatio-temporal variability of quarterly GWL and the HGC controls regulating it during the 1995-2015 period over a data-scarce tropical savanna region in India. Using data mining techniques, the study evaluated land use land cover (LULC), geomorphology, lithology, topography and rainfall as HGC controls for GWL variability. The analysis revealed that this region has high intra-annual spatial variability characterized by higher GWL variability in the drier period of the year than wet period. The temporal analysis of GWL demarcated the distinct regions with highly significant rising and declining trends with magnitude ranging from -0.51 to $0.42 \mathrm{~m} /$ year. It was discovered that the LULC could explain the observed GWL variability at the highest degree compared to the other considered HGC controls. Subsequently, through principal component analysis (PCA) six representative components covering more than $90 \%$ of the variance in 2002 LULC dataset were used for training the random forest $(\mathrm{RF})$ learning algorithm to develop four prediction models corresponding to four temporal quarters. The PCA-RF based trained prediction models showed adequate accuracy during testing using the 2005, 2010, and 2015 LULC datasets. The developed models were further used to make short- and long-term GWL predictions in the study region. The developed models can contribute to regional-scale groundwater planning and management in data-scarce tropical regions.
\end{abstract}

\section{Novelty and International Appeal Statement}

Through understanding on spatio-temporal variability of groundwater level in tropical savanna climatic region with heavily stressed aquifers and its hydrological, geological, and climatic (HGC) controls, has immense role in long-term sustainable management of the resource. This study attempts to develop prediction model for GWL taking the dominant HGC control as explanatory variables using ML algorithm. To achieve the aforesaid objective, firstly the spatio-temporal variability of GWL in the study region was comprehended and the dominant HGC controls for observed spatio-temporal variability were identified using entropy approach. To the best of our knowledge this study is the first of its kind in groundwater variability prospective. Further, the grid-wise relationship among the groundwater level and the features in the dominant HGC control was established using Random Forest learning algorithm to make short- and long-term predictions of GWL with reasonable accuracy in the study region with limited data. The proposed framework is a novel attempt to characterize spatio-temporal variability in GWL in tropical regions with highly heterogeneous aquifers and predict the future trends in GWL at regional level.

\section{Hosted file}


HP_Manuscript_shortened.docx available at https://authorea.com/users/360109/articles/481821projecting-groundwater-variability-in-data-scarce-tropical-savanna-region-of-india

\section{Hosted file}

HP_Declaration-of-competing-interests.docx available at https://authorea.com/users/360109/ articles/481821-projecting-groundwater-variability-in-data-scarce-tropical-savannaregion-of-india

\section{Hosted file}

HP_Tables-1.docx available at https://authorea.com/users/360109/articles/481821-projectinggroundwater-variability-in-data-scarce-tropical-savanna-region-of-india

\section{Hosted file}

HP_Tables-2.docx available at https://authorea.com/users/360109/articles/481821-projectinggroundwater-variability-in-data-scarce-tropical-savanna-region-of-india

\section{Hosted file}

HP_Tables-3.docx available at https://authorea.com/users/360109/articles/481821-projectinggroundwater-variability-in-data-scarce-tropical-savanna-region-of-india

\section{Hosted file}

HP_Tables-4.docx available at https://authorea.com/users/360109/articles/481821-projectinggroundwater-variability-in-data-scarce-tropical-savanna-region-of-india

\section{Hosted file}

HP_Tables-5.docx available at https://authorea.com/users/360109/articles/481821-projectinggroundwater-variability-in-data-scarce-tropical-savanna-region-of-india

\section{Hosted file}

HP_Tables-6.docx available at https://authorea.com/users/360109/articles/481821-projectinggroundwater-variability-in-data-scarce-tropical-savanna-region-of-india 


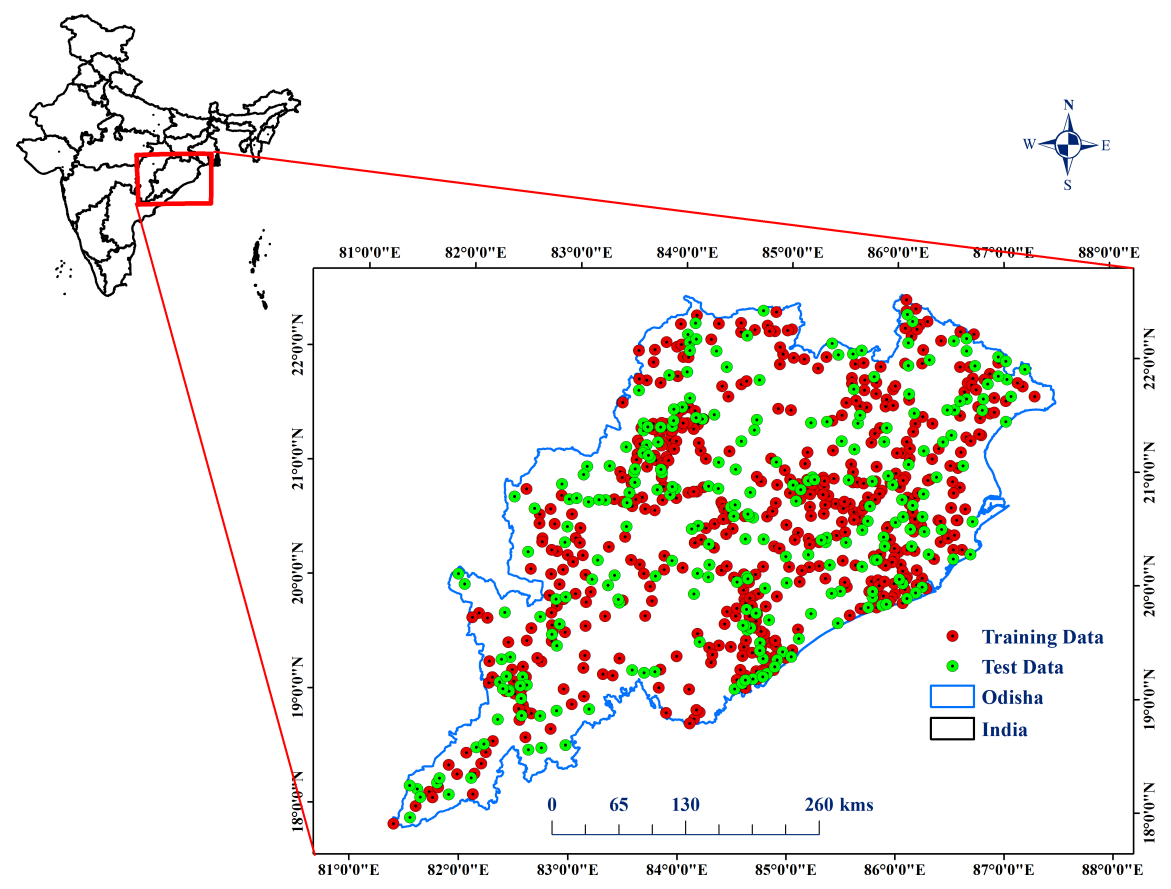




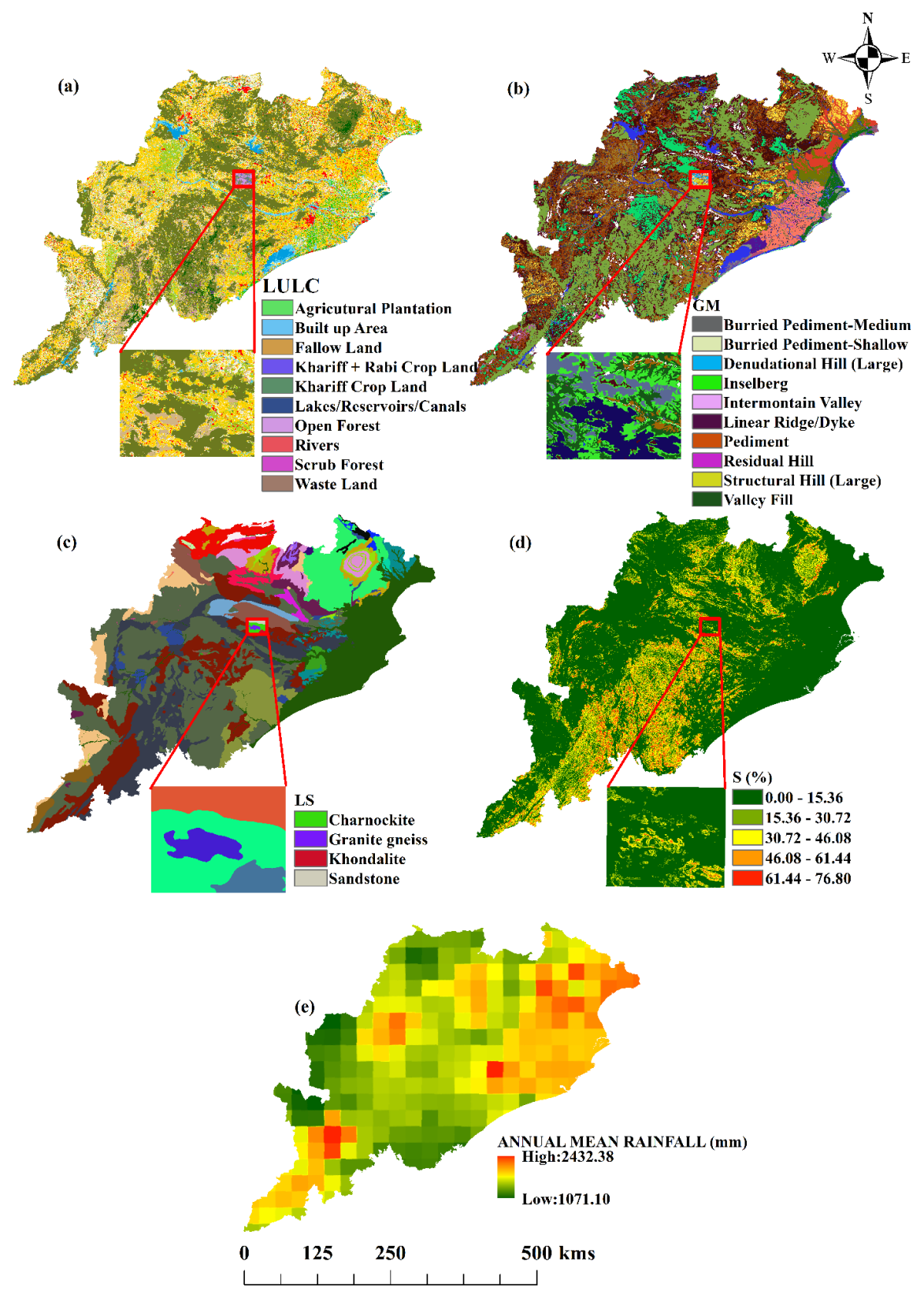



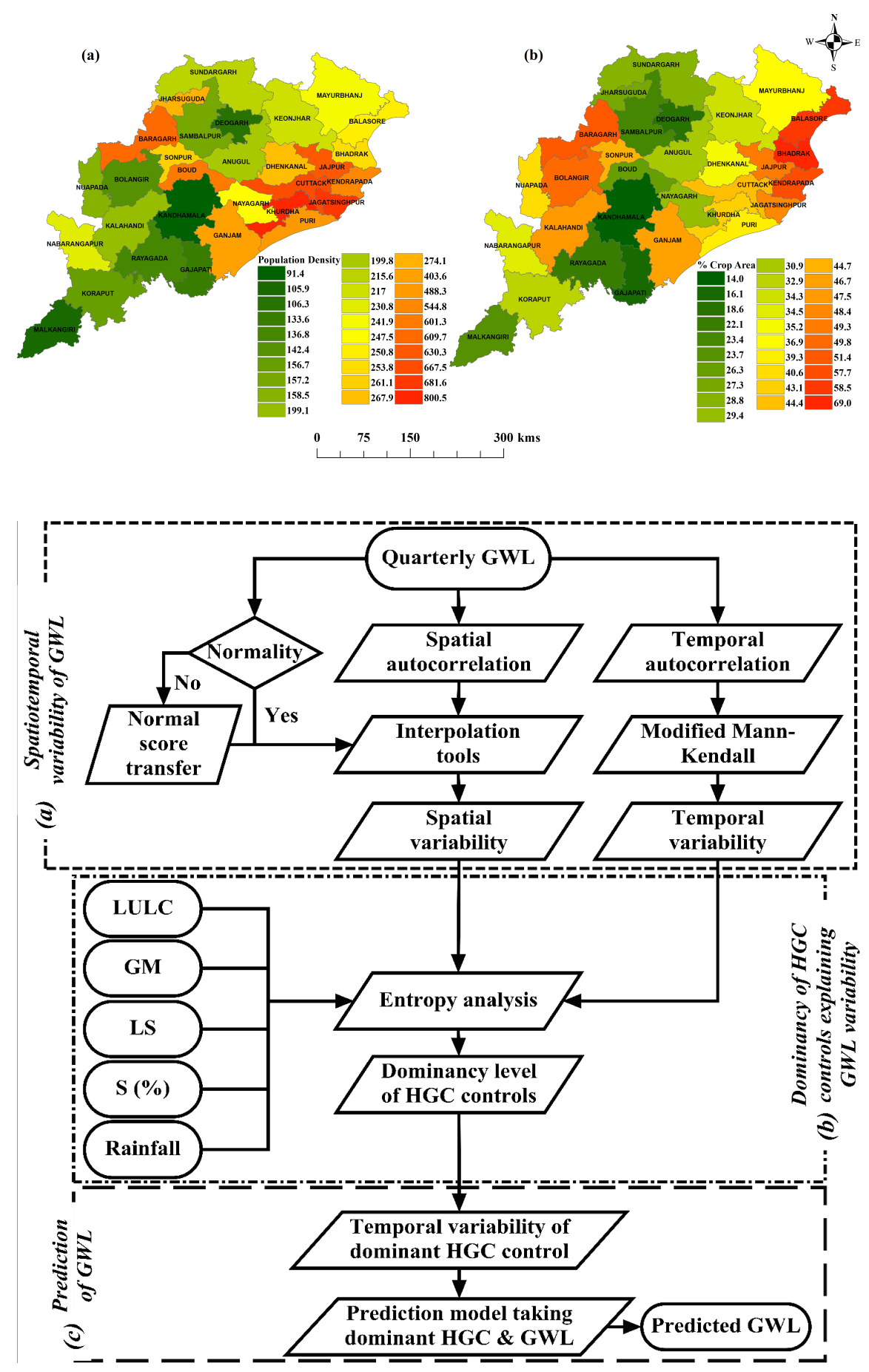


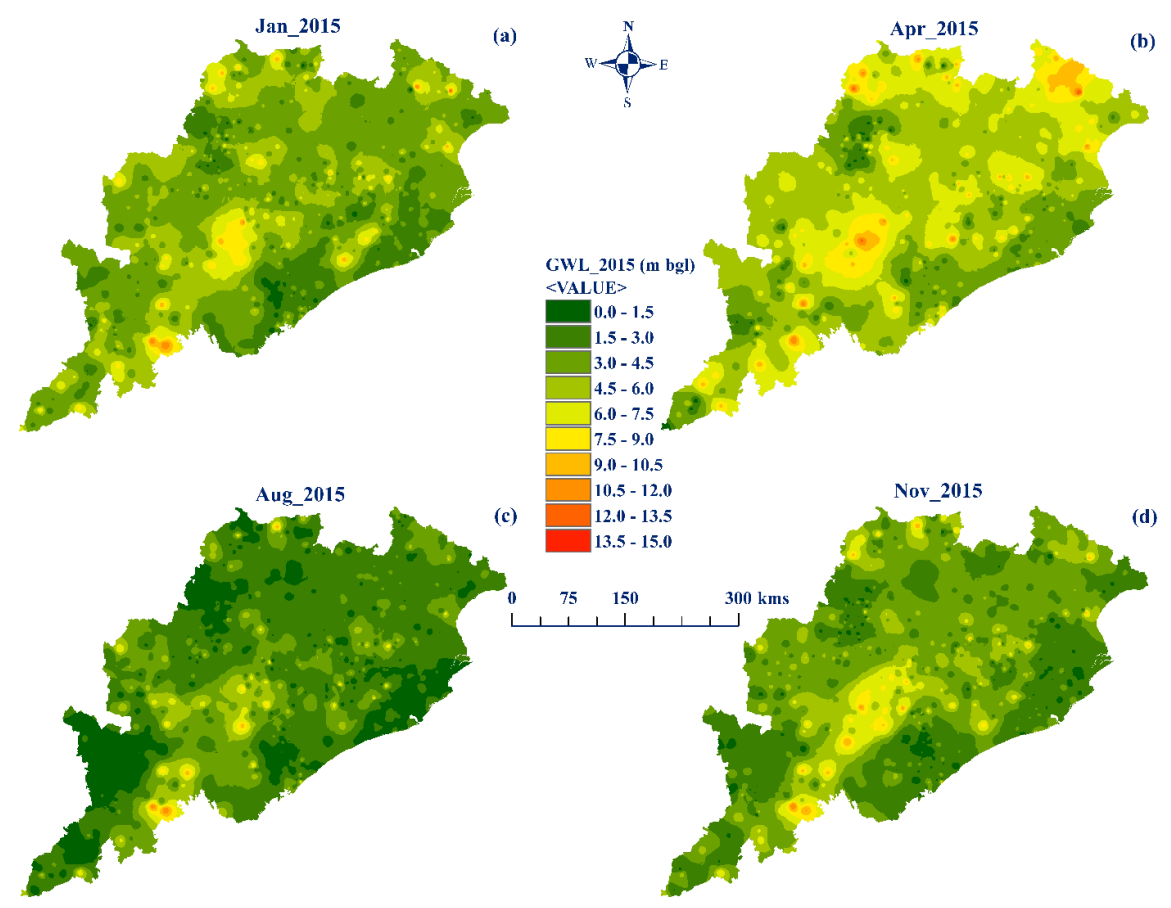



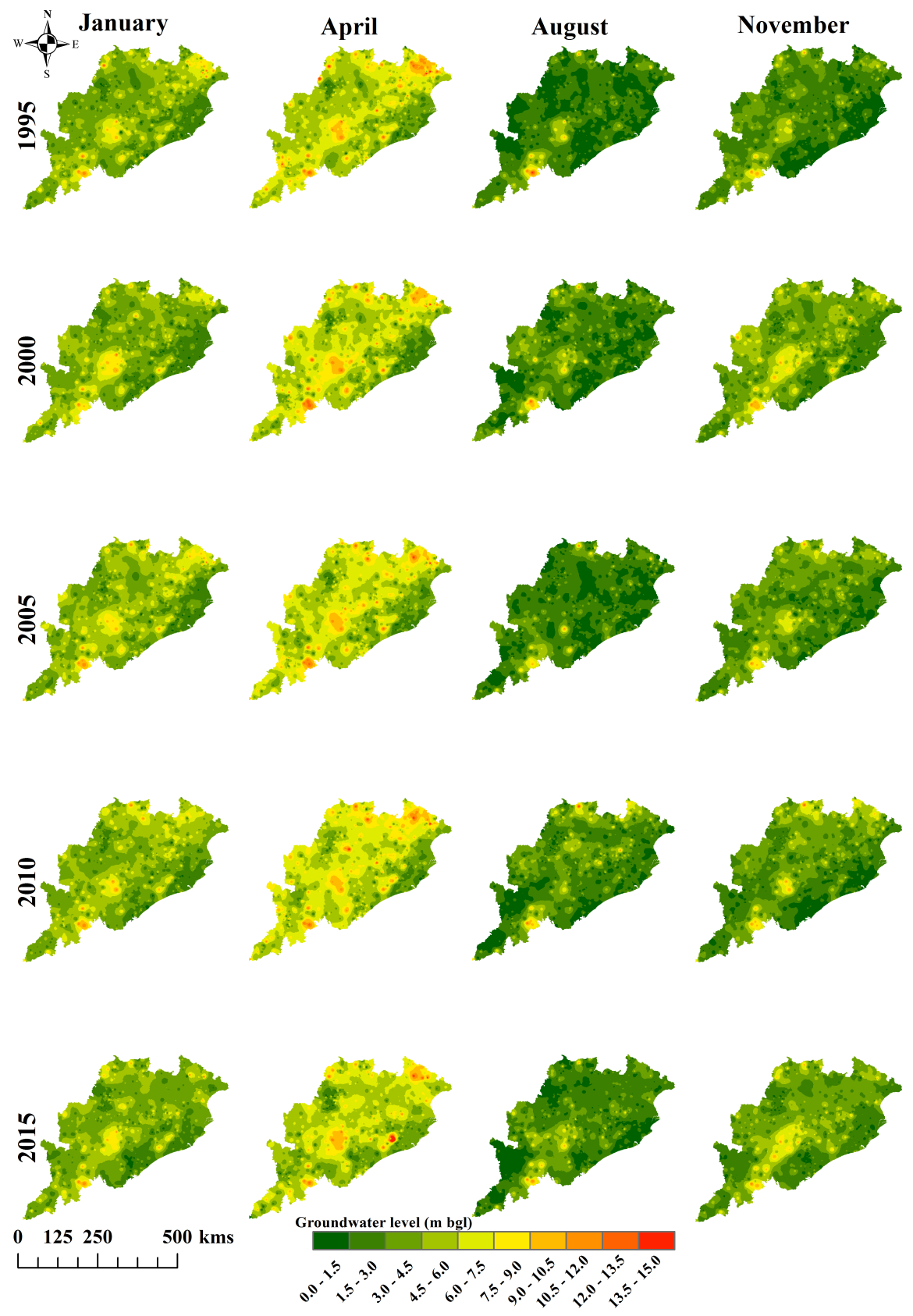

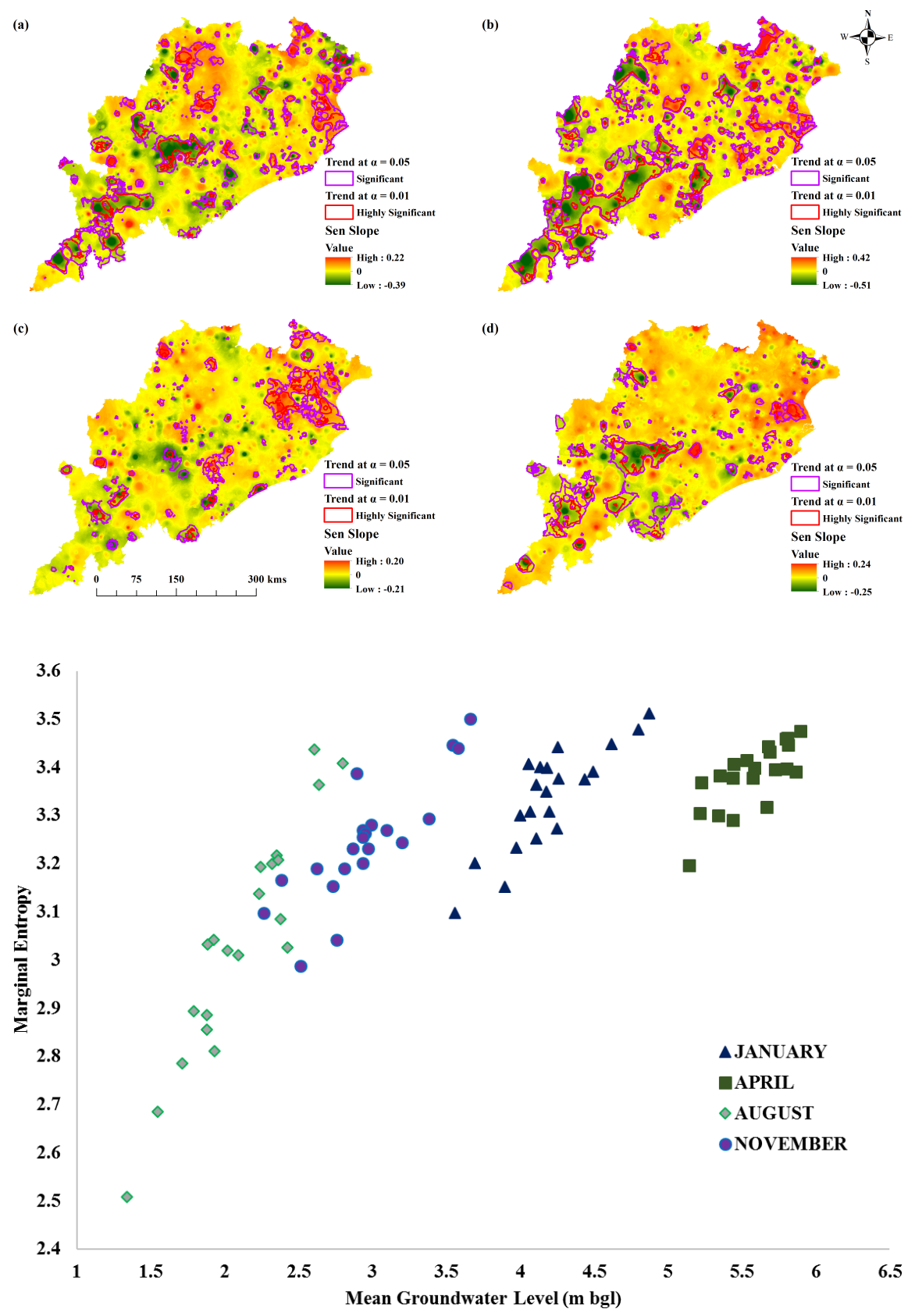

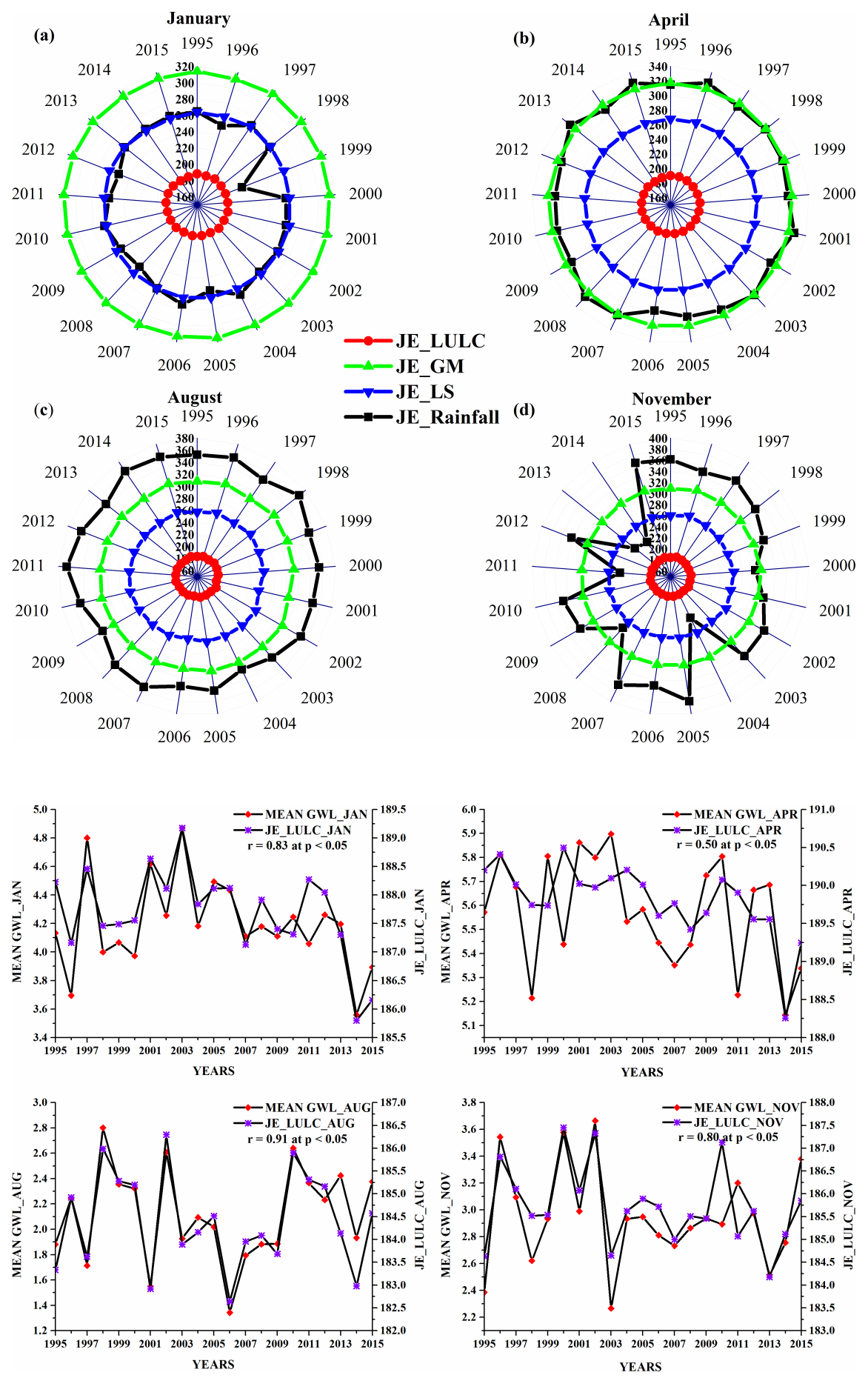

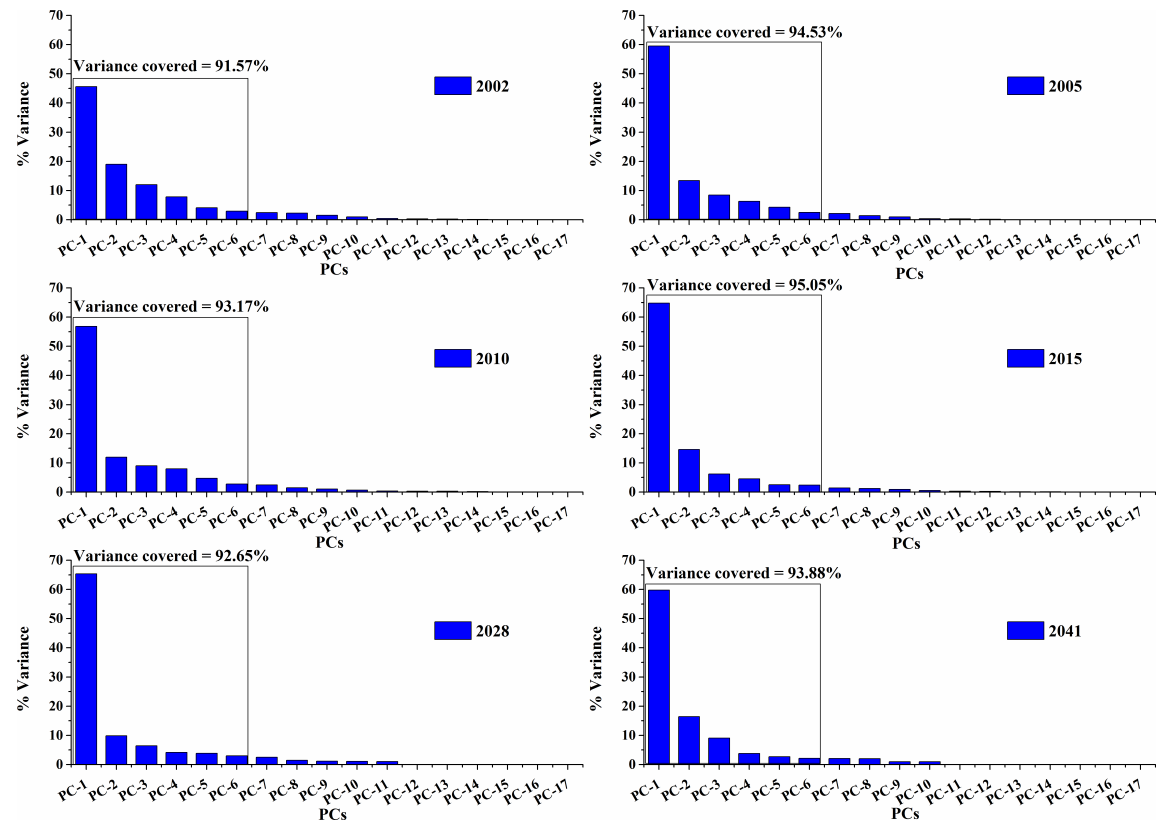

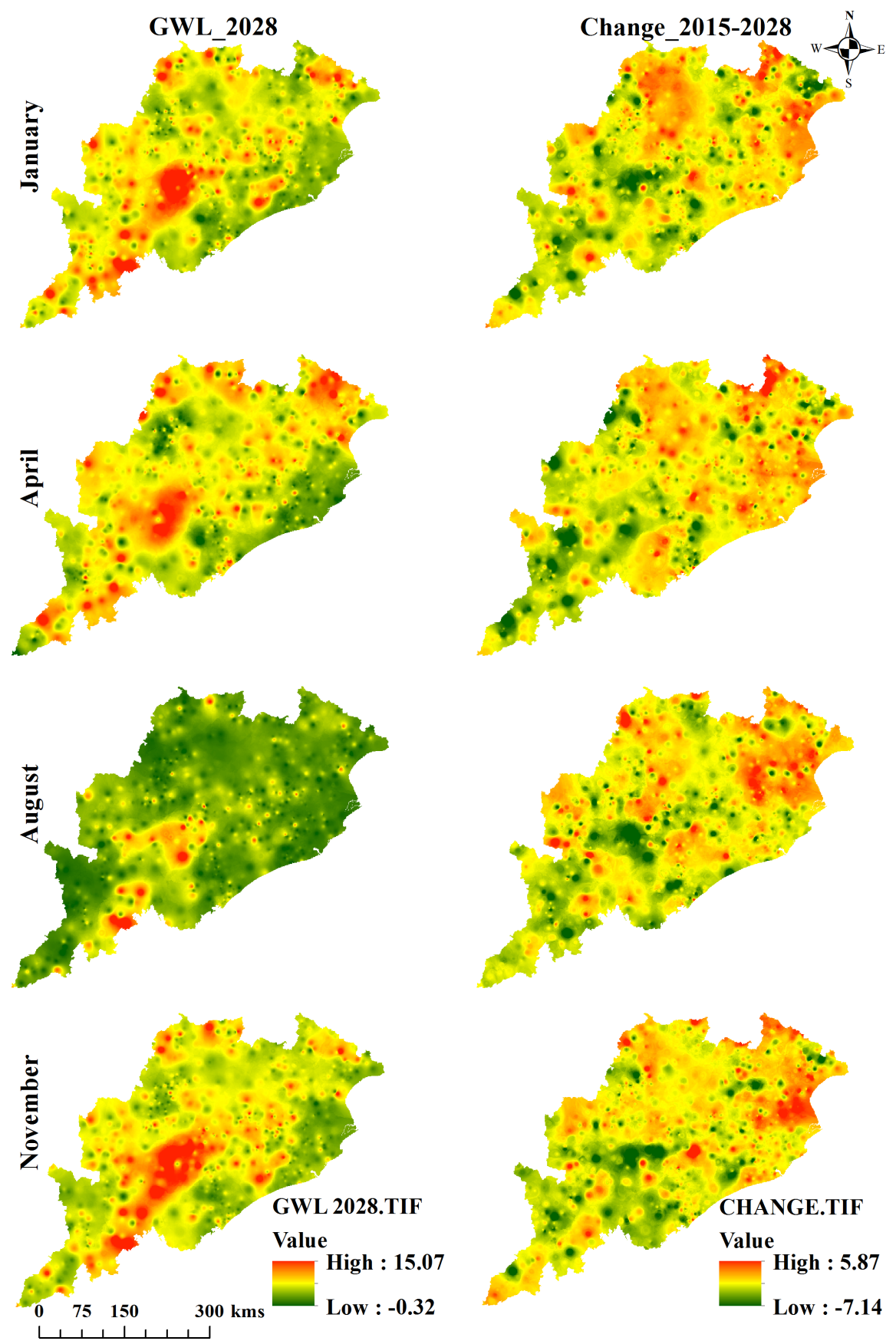